\title{
IDENTITET I/KROZ SPORT: ANTROPOLOŠKI PRISTUP ISTRAŽIVANJU DIJASPORE
}

TIBOR KOMAR

Filozofski fakultet Sveučilišta u Zagrebu

Odsjek za etnologiju i kulturnu antropologiju

10000 Zagreb, Ivana Lučića 3
DOI: $10.17234 /$ SEC.27.10

Izvorni znanstveni rad /

Original scientific paper

Primljeno / Received: 1. 3. 2015.

Prihvaćeno / Accepted: 7. 8. 2015.

Kroz prizmu sporta, specifičnije nogometa, autor u nekoliko segmenata propituje vezanost sporta i identiteta u dijasporskim zajednicama. Nakon uvodnog dijela gdje predstavlja kratku povijest istraživačkog $i$ znanstvenog interesa za sport u antropologiji i srodnim znanostima, dalje se analiziraju elementi procesa konstrukcije nacionalnog identiteta u hrvatskoj dijaspori vezani uz amaterski i profesionalni nogomet.

Ključne riječi: identitet, sport, nogomet, dijaspora

\section{UVOD}

Vjerojatno jedno od prvih pitanja koje će se nametnuti čitatelju jest ono u kojoj mjeri sport, ili još konkretnije nogomet, može poslužiti kao predmet istraživanja društveno-humanističkih znanosti. Odgovora ima mnogo i dolaze s različitih gledišta, poput onog koji cilja na opću popularnost nekog fenomena, a kojeg daje Pascal Boniface (2002) u svojoj knjizi Geopolitika nogometa: "Nogomet je u svijetu rašireniji nego demokracija, internet ili pak tržišna ekonomija." No, daje li mu upravo ta društvena sveprisutnost legitimitet da ga se istražuje kroz antropološku prizmu ono je čega ćemo se pokušati dotaknuti u ovom radu. Ako kao jednu od općih funkcija sporta razmotrimo pretpostavku da on često djeluje kao mehanizam nacionalne solidarnosti promovirajući osjećaj identiteta i zajedništva (usp. Mangan 1996), nogomet se na više razina pokazuje kao idealan poligon za istraživanje simboličkih dimenzija pripadnosti, diskurzivnog oblikovanja identiteta i praksi kojima se oblikuje (sportska) nacionalna lojalnost. Tako neodvojivi dio bavljenja sportskom tematikom uključuje i nacionalni identitet kao aspekt istraživanja koji u društvenohumanističkim znanostima, posebice u etnologiji i kulturnoj antropologiji, posljednjih nekoliko desetljeća ponovno zauzima vrlo visoku poziciju. 
Kao uzrok toga povećanoga znanstvenog zanimanja za pitanja identiteta vjerojatno bi se mogla navesti i europska politička situacija u posljednja dva desetljeća koja je nakon raznovrsnih političkih previranja iznjedrila veći broj "novih" nacija i država koje su svoje (geo)političko mjesto pokušavale potvrditi (ponajprije) i na polju sporta.

Iako je sama povijest sporta dugovječna, njegovo dovođenje u sferu društveno-humanističkoga znanstvenog interesa nije se dogodilo sve do sredine 20. stoljeća, a i tada većinom u sociološkim krugovima. Perasović i Bartoluci navode da "proces institucionalizacije discipline u svijetu počinje sredinom 60-ih godina 20. st. kada sveučilišni profesori tjelesnog odgoja uviđaju važnost sporta kao društvene pojave i njegovu kulturnu i povijesnu uvjetovanost" (Perasović i Bartoluci 2007:106). Službenim počecima znanstvenog istraživanja sporta konsenzualno se smatra djelo njemačkog znanstvenika Heinza Rissea Soziologie des Sports objavljeno 1921. godine. No, prošlo je gotovo pola stoljeća nakon njegova izdavanja dok međunarodna skupina sociologa nije osnovala odbor ${ }^{1}$ i časopis ${ }^{2}$ za proučavanje mjesta sporta u društvu. Tek nakon toga, mnoga sveučilišta uspostavljaju centre za istraživanja u kontekstu sociologije sporta.

Kad govorimo o (kulturnoj) antropologiji, situacija je pomalo drugačija jer sport nalazi svoje mjesto u suvremenim istraživanjima nešto kasnije nego u sociologiji. Ako zanemarimo cjelovite etnografije koje su se u povijesti struke djelomično doticale sporta ili igara, tek su se 80-ih godina 20. stoljeća počela postavljati ozbiljna pitanja o mjestu sporta u antropološkim istraživanjima. Antropološka znanost, i sama osnovno definirana kao ona koja teži proučavanju svih aspekata ljudskog ponašanja, nudi nam jednostavnu definiciju sporta kao "igrolike aktivnosti koja ima pravila, natjecateljski karakter te zahtijeva neku vrstu fizičkog napora" (Blanchard 1995:9). Antropologinja Catherine Palmer sport opisuje kao "kulturni fenomen koji priziva strast, pogoni gospodarstva, oblikuje politiku, ističe nejednakosti i naglašava nacionalne, regionalne i nacionalne identitete" (2002:253). Razmatrajući različite pristupe i pokušaje

\footnotetext{
${ }^{1}$ International Committee for the Sociology of Sport (ICSS), 1965.

${ }^{2}$ International Review for the Sociology of Sport (IRSS), 1966.
} 
klasificiranja sporta, oslonit ću se ovdje na prilog švicarskog teologa i filozofa Denisa Müllera (usp. 2004) koji u jednom od svojih tekstova prenosi tipologiju filozofa Heinza Wismanna o postojanju tri vrste sportova - prva su sportovi borbe ili sile (Kraftsporte) karakteristični za antiku, srednji vijek i renesansu (poput atletike ili boksa). U drugu vrstu spadali bi sportovi kolektivnog sukobljavanja, timski sportovi ili sportovi s loptom tipični pak za industrijsku modernu poput nogometa, ragbija, rukometa, košarke ili hokeja na ledu. Naposljetku dolaze sportovi postmodernog razdoblja kao što su skijanje ili snowboarding. Müller, međutim, smatra da se ovakvoj interpretaciji može zamjeriti idealno-tipska podjela jer to što neki sportovi egzistiraju na margini ne umanjuje njihovu važnost. Primjerice, imamo sportove poput odbojke koja uvodi novi element mrežu koja pak sugerira prijelazni oblik između druge i treće kategorije sporta, u toj mjeri da mreža uspostavlja fiksnu podjelu između dva tabora te čini sukob i nasilje nad tijelom u potpunosti simboličkim. U istom smislu, tenis mijenja razdvajajuću funkciju mreže tako da dodaje već spominjani element antičke atletske snage. Sa svoje pak strane, skijanje uvodi "mrežu" na nevidljiv način, kombinirajući samoću natjecatelja s idejom simboličnog paralelizma putem istodobnog spusta dvojice natjecatelja ili pak nadodavanjem televizijske snimke na prethodnu slalomsku vožnju.

Budući da je u povijesti antropologije sport često bio guran u kategoriju "igara", svakako treba spomenuti i Edwarda Burnetta Taylora koji je među prvima prepoznao važnost upravo igre kao predmeta antropološkog istraživanja. Taylor je shvatio da društvene aktivnosti poput sportskih događaja mogu pružiti antropologu važne tragove o prirodi pretpovijesnoga kulturnog kontakta te već u radu iz 1879. godine pod naslovom The History of the Games predstavlja ideju da se neke igre (loptom) mogu koristiti kao dokaz difuzije i kontakta između kulturnih centara u različitim dijelovima svijeta jer su toliko "umjetne" da su teško mogle nastati na udaljenim geografskim područjima (Blanchard 1995:10). Dakle, možemo zaključiti kako između antropologije i (suvremenog) sporta postoje drevni odnosi afiniteta, od njegova "rođenja" u moderni krajem 19. stoljeća do današnjih dana. U prvom izdanju knjige Anthropology of sport - an introduction iz 1985. godine Kendall Blanchard i Alyce Cheska 70-ih i 80-ih godina započinju stvarati prvi sustavni teorijski pristup antropološkog istraživanja sporta, tzv. inside story, koji izrasta iz njihova terenskog 
istraživanja košarke kod Navajo Indijanaca. Desetak godina kasnije, radovima Roberta Sandsa pojašnjava se odnos etnografije i antropologije te uspostavlja jasan etnografski i komparativni pristup. Sands je proveo tri godine uz nogometnu (američki football) momčad u Santa Barbara City Collegeu igrajući i proučavajući ovu igru "iznutra” kada je s 37 godina postao rezervni branič ove momčadi. Zanimljivo je da njegova etnografija nije bila "egzotična" nego se odvijala "kod kuće" te imala za cilj istražiti jedan specifičan segment američke kulture. Takva razmatranja, koja su na tragu interpretativnog, omogućuju stvaranje raznih etnografskih okvira kroz koje antropološki možemo tumačiti značenje i ulogu igre u raznim ljudskim društvima. Iz svih tih okvira proizlazi kompleksna slika antropologije kao skupa teoretskih i praktičnih postupaka koji teže shvatiti sva moguća stajališta čovjekovih svjetova. Dakle, "stari" su antropolozi proučavali sport većinom u kontekstima egzotičnih aktivnosti života predmodernih vremena gdje sport nije samo sport nego igra, učenje, ritualna inicijacija, društvena interakcija, povijesni prežitak ili pak simbolički performans prilično različito od onoga kako ga mi danas doživljavamo.

Općenito govoreći, nogomet je vjerojatno jedan od antropološki ponajviše proučavanih sportova, kako u zemljama klasične "loptačke" tradicije tako i u onima gdje je "uvezen". Njegovo antropološko proučavanje započinje s praksom etnografskog promatranja sa sudjelovanjem, a metodološki zrelije studije, većinom europske, često pokušavaju analizirati nogomet kao način života i simboličku praksu koja se odnosi na "rituale rata" i "vjerske obrede". Moglo bi se reći da ti obredi spajaju sport s društvom u cjelini, kao svojevrsna interakcija između igrača i javnosti, institucija i sportskog menadžmenta stvarajući kondenzaciju simbolā i subjektivne identifikacije. Francuski antropolog Christian Bromberger, jedan od europskih pionira suvremenog istraživanja antropologije sporta, navodi zgodnu anegdotu kako je 1985. godine pri početku projekta istraživanja nogometa u Francuskoj njegov tim istraživača redovito dobivao posprdne komentare poput: "Ah, nogomet... Zar nemate nešto pametnije za istraživati?" (Bromberger 1995:5). No, kao bitan element popularne kulture i najpopularniji svjetski sport, nogomet je sveprisutan u hrvatskom društvu. Medijske reprezentacije nogometnih događaja (ne samo oni "važnih") jesu znatne i one samo odražavaju status igre u svakodnevnom diskursu, posebice muškog dijela populacije, a vezana popularnost igre te količina 
kako improviziranih tako i uređenih nogometnih igrališta omogućuje znatno igranje nogometa te promatranje i uživanje u njemu. Svakodnevna prisutnost i blizina ove igre omogućila je pak vezivanje uz momčad iz ulice, kvarta, škole, tvrtke, grada, regije ili nacije, a u današnje vrijeme sve više i uz momčad iz drugoga grada, regije, države pa čak i nacije - primjeri mogu biti suvremena popularnost Barcelone ili reprezentacije Brazila u zemljama jugoistočne Europe.

Sa stajališta etnografije, nogomet vjerojatno i nije dovoljno proučavan sport jer unatoč velikoj proizvodnji radova u svijetu kojom se ovaj sport može pohvaliti tek predstoji adekvatno proučiti sve načine na koje se nogomet "utjelovljuje". Tu svakako kao primjer treba spomenuti njegovu ulogu u konstrukciji identiteta afričkih i arapskih naroda ili pak njegov uzlet u posljednjih dvadesetak godina na tlu Sjedinjenih Američkih Država gdje ga konzervativne političke snage čak pokušavaju ocrniti na više razina - smatrajući da je rast popularnosti nogometa znak moralnog propadanja američke nacije te označavajući nogomet svojevrsnim kolonijalnim remetilačkim elementom koji ima za cilj uništiti "svetost" američkoga nacionalnog sporta koja se ogledava u footballu, košarci, baseballu i odbojci. ${ }^{3}$ Također, na polju uspostavljanja društvenih granica spola, rase i identiteta postoji još mnogo prostora za istraživanja, kao i na polju sportske performativnosti koja se realizira kroz sve veću medijsku "sportizaciju".

\section{NOGOMET I IDENTITET}

U svakom slučaju, nogomet je važan identitetski okvir dijela populacije, a klubovi su bitni simboli npr. grada ili regije. U njegovoj identitetskoj važnosti, simboličkom potencijalu te tako i sredstvu razlikovanja od drugih krije se i jedan od razloga popularnosti nogometa.

\footnotetext{
3 http://www.clarionledger.com/story/opinion/columnists/2014/06/25/coulter-growinginterest-soccer-sign-nations-moral-decay/11372137/

${ }^{4}$ Pojam je uveo N. Elias kako bi objasnio uvođenje kodova i pravila u sportsko ponašanje, ponajviše u cilju odmaka od nasilja - npr. uvođenje rukavica u boks pravilnikom Queensberry rules iz 1867. godine.
} 
Svakako ovdje treba spomenuti ritualnost i religičnost nogometne igre. Za Müllera (2006), nogomet je u globalnom javnom prostoru preuzeo ulogu kvazireligije te je nemoguće ignorirati njegovu religijsku dimenziju i teološko značenje. Müller se također osvrće na antropološku važnost nogometa te u tom smislu razvija njegove četiri bitne karakteristike: igra, natjecanje, spektakl, simbol. Za njega, nogometna igra jest ta koja priziva dječju strukturu postojanja, podsjećajući nas na slobodno bivanje na svijetu. Trčati za loptom, nadigrati protivnika, dati gol - to su kreativni performansi koji se zrcale u stvarnom svijetu. No, nogomet je i natjecanje koje rađa pobjednika i gubitnika, rađajući time određeno simboličko nasilje. U industrijskom i komercijalnom svijetu, naglašenom globalizacijom, to čisto sportsko natjecanje ujedinjuje želju za nacionalnim prestižem i imperativ gospodarskog rasta. Nadalje, nogomet je spektakl i to u dvostrukom smislu: nogometna igra jest tragedija u aristotelovskom smislu jer "angažirani gledatelj" u njoj pronalazi elemente katarze i straha (grč. katharsis i phobos) - drugim riječima, gledatelj prolazi kroz "čišćenje" preplitanjem impulsā postignuća i sublimacijom strahova od smrti. Tijek nogometne utakmice također je spektakularna i reflektirajuća borba za život, smrtna borba između snaga razaranja i snaga solidarnosti koje dijele ljudski svijet. Kao četvrti element, za Müllera je nogomet simbol temeljne ambivalentnosti čovjeka $-\mathrm{s}$ jedne strane rastrganog između svoje samoće i potrebe za solidarnošću, a s druge strane, između afirmacije sebe kao "drugog” i želje da se uništi "drugog" kao prepreku na putu samoostvarenja. Na sličnom tragu je i Elias (1966) navodeći kako je nogomet sport koji najbolje predstavlja najvišu razinu civilizacije modernog društva kroz 22 igrača na terenu i gotovo bezbroj konfiguracija u kojima se oni mogu naći - stvarajući istodobno red i kaos. Upravo takva dinamika stvara nove prostore koji se pomiču, sužavaju ili otvaraju, ali uvijek u okvirima pravila igre. Također, nogomet stvara i određeni emocionalni prostor između igrača i gledatelja pa tako "visoko civilizirani uređeni nered i opuštajuća napetost nogometne utakmice vode publiku do kolektivne katarze" (Elias, prema Frank i Steets 2010:3). Identifikacijsku snagu te simboličku važnost nogomet izrazito prikazuje na nacionalnoj razini, osobito pak u zbivanjima u kojima sudjeluje seniorska reprezentacija određene zemlje (primjerice Svjetsko prvenstvo u nogometu ili kvalifikacije za Europsko prvenstvo u nogometu). Pri tome treba primijetiti da se ustrojavanje nogometa i njegovo širenje svijetom 
odvija upravo u vrijeme stvaranja nacionalnih država (kraj 19. i početak 20. stoljeća), pa se nogometu od modernog početka pruža mogućnost da posluži kao simboličko i identitetno sredstvo novih nacija koje za takvim fenomenima upravo i žude. Nogomet se također izvrsno uklapa u potrebu novih nacija da ujedine različite ljude u "zamišljenu zajednicu" (Anderson 1983). Važnost nogometa za Hrvatsku u određenoj mjeri odražava i činjenica što je nacija u formiranju 1990-ih trebala simbole identiteta, pojave koje populaciju povezuju i stvaraju osjećaj jedinstva, a upravo kad su se simboli identiteta u Hrvatskoj stvarali, njezina nogometna reprezentacija postizala je iznimno dobre rezultate (vrhunac je treće mjesto na Svjetskom prvenstvu 1998. godine), izazivala nacionalnu euforiju te slavlja po ulicama i trgovima diljem zemlje - popraćen dobrim rezultatima reprezentacije, nogomet je u Hrvatskoj svakodnevici postao važan dio kolektivne i državne simbolike. Brentin (2013) navodi kako u to vrijeme započinje proces tijekom kojeg sport postaje važan nacionalizirajući i homogenizirajući faktor u nekim jugoslavenskim republikama. Još značajnije, ishod izbora 1990. i slijedom toga proglašavanje hrvatske neovisnosti te dolazak Hrvatske demokratske zajednice na vlast dovodi do ozbiljnog narušavanja etničkog razumijevanja. Sportaši su "bili dužni" na svoj način voditi uzvišenu borbu za hrvatsku neovisnost te tako sudjelovati u izgradnji nacionalnog identiteta. Sport je usvojio funkciju ključnog simbola za stvaranje posebnoga hrvatskog nacionalnog osjećaja gdje su i sami sportaši stalno tvrdili da je natjecanje u ime nacije više od "samo" sporta (usp. Brentin 2013).

Štoviše, Richard Giulianotti (usp. 1999:23) smatra da je upravo "nogomet jedna od velikih kulturnih ustanova, poput obrazovanja i masovnih medija, koji oblikuje i cementira nacionalne identitete u cijelom svijetu" što savršeno odgovara ideji moderne nacije i modernog svijeta, kada se osjećaj nacionalnog jedinstva stvarao kako političkim, prometnim, institucionalnim integriranjem, tako i onim obrazovnim, kulturnim te, između ostalih i ne manje važnim, sportskim. Još jedan pojam koji se usko veže uz istraživanje identiteta je nacionalizam. U svojoj knjizi posvećenoj stvaranju engleskoga nacionalnog identiteta, Krishan Kumar (2003:21) objašnjava nacionalizam kao specifičnu vrstu politike koja se generira tamo gdje politički pokreti koji traže ili obnašaju državnu vlast opravdaju svoje djelovanje pripisivanjem specifično nacionalističkog značenja simbolu "nacije". U suštini, nacionalistička ideologija poprima oblik tvrdnje da 
postoji nacija s eksplicitnim i osebujnim karakteristikama, a jedna je od mnogih u svijetu, svaka sa svojom individualnošću, poviješću i sudbinom. Nacija tako biva izvor sve političke snage, a vjernost njoj nadjačava sve ostale odanosti i njezini interesi imaju prednost pred svim ostalim interesima i vrijednostima. Ideja osebujne nacije jest eksplicitna osnova političkih zahtjeva nacionalista te se često temelji na središnjoj ideološkoj tvrdnji nacionalističkih pokreta da je nacija u ozbiljnoj opasnosti (usp. Kumar 2003). Današnji sportovi ipak su rezultat procesa modernizacije u kojem su tradicionalni rekreacijski oblici reformirani i restrukturirani, pri čemu se promijenilo i njihovo značenje. Igre su u procesu širenja donekle izgubile svoje lokalne i klasne asocijacije te postale homogene i standardizirane. Štoviše, postale su univerzalne, a najočitiji primjer toga svakako je nogomet koji se iz Britanije raširio svijetom (Hargreaves 2000:12-13). U procesu modernizacije različiti su sportovi zauzeli središnja mjesta u popularnim kulturama različitih društava - nogomet tako učvršćuje izgradnju nacionalnih identiteta diljem Europe i Latinske Amerike, dok je kriket sličnu ulogu preuzeo u zemljama Commonwealtha poput Indije, Pakistana i Bangladeša. Sličnu ulogu odigrao je i kod alžirskih nogometnih klubova koji su postali središta otpora francuskom kolonijalizmu kroz korištenje nostalgije, mitologije, izmišljanja tradicije, zastava, himni i ceremonija. U Britaniji je sport postao dio mitologije o nacionalnom identitetu, pa se privrženost sportu i vrijednostima fair-playa koje on navodno usađuje još uvijek smatraju osobinama koje Britance razlikuju od drugih (Hargreaves 2000:13). Koković tvrdi da države koje steknu nezavisnost upravo preko sporta traže svoje mjesto u međunarodnoj zajednici, dok one superiorne u njemu traže potvrdu svoje moći i interesa. Sport u određenoj mjeri aktivira grupne veze i daje mogućnost nacijama da se užive i identificiraju sa svojom grupom, a na taj način sport se koristi kao socijalno sredstvo grupne integracije, način buđenja patriotskih i nacionalnih osjećaja (Koković 1986:95). Problematika koncepta nacionalnog identiteta vrlo se lako dalje prenosi iz političkog diskursa u onaj sportski i premda postoji određen konsenzus oko toga da je nacija odvojena od ostalih oblika kolektivnih identiteta kao što su klasa, rod ili rasa, postoji i razumljivo neslaganje oko skupa obilježja koji konstituiraju naciju. Objektivne značajke poput teritorija, religije i jezika valja uklopiti u niz subjektivnih obilježja poput zajedničkog osjećaja povijesti i mitologije. Primjerice, moderna Njemačka, 
osobito od ujedinjenja, suočila se s različitim problemima u pronalaženju nacionalnih simbola koji nisu okaljani nacizmom ili koji ne slave relativno nedavne pobjede nad aktualnim saveznicima (osobito Francuskom) ili moćnim susjedima (kao što je Rusija). U nedostatku praktičnih povijesnih simbola Njemačka je s oduševljenjem prihvatila sportske zvijezde poput Borisa Beckera, Katrin Krabbe, Jürgena Klinsmanna, a posebno Michaela Schumachera, kao simbole novog identiteta zemlje. Slijedom toga, sport, a osobito elitni sport, koristi se kao fokus za definiranje nacionalnog identiteta, koji se, nakon što je uspješno uspostavljen, često projicira natrag za poticanje dojma kulturnog kontinuiteta (Nauright 1995). Ne samo da je elitni sport raznovrsniji nego isto tako može biti učinkovitije izoliran od pojedinih etničkih kultura (Houlihan 2000:129). Nacionalni sport uvelike se fokusira na nacionalno jedinstvo i identitet, vodeće dominantne vrijednosti, ideale i resurse u naciji iz koje dolazi pa tako sport kao dio svakodnevnog života omogućuje nacionalnu identifikaciju "bez puno promišljanja" (Kotnik 2009:53). Nedvojbeno, to je razlog zašto sportovi koji nisu uspješni na međunarodnoj sceni ne mogu uspješno funkcionirati kao čvorišta nacionalne identifikacije.

\section{DIJASPORA, IDENTITET I SPORT}

Za Vertovca (1999), “dijaspora" je pojam koji se često koristi za opisivanje zapravo bilo koje populacije koja se smatra "deteritorijaliziranom" ili “transnacionalnom”, tj. koja je proizašla iz zemlje različite od one u kojoj se trenutačno nalazi te čije socijalne, ekonomske i političke mreže prelaze granice nacionalnih država ili, štoviše, premrežavaju svijet (Vertovec 1999:1). Brubaker (usp. 2005) tvrdi da velik broj recentnih studija povezanih s dijasporom dovodi do toga da termin već pomalo gubi svoj smisao. Unatoč ovoj ekspanziji u akademskoj zajednici i široj uporabi pojma, Brubaker identificira tri temeljna elementa koja su osnova korištenja pojma dijaspore. To su raspršenost, orijentacija domovini i održavanje granica. On tvrdi da ti elementi doprinose inače problematičnom razumijevanju dijaspore kroz pretpostavku skupine gdje je osjećaj identiteta omeđen i na taj način pretpostavlja univerzalni karakter ili osjećaj pripadnosti. To je u suprotnosti s "nacijom-državom" jer je njezino značenje na sličan način 
povezano s definicijom koja je idealizira kao homogenu i kao proizvod sociološke imaginacije. Umjesto toga, Brubaker (2005:12) upozorava da bismo trebali promišljati nacije kao fragmentarne i raznolike. Kada govorimo o bilo kojoj iseljeničkoj zajednici, sport je jedan od bitnih kanala održavanja povezanosti s matičnom državom. Transnacionalne veze obično stvaraju ono što Clifford naziva "multilokalna kultura dijaspore" među raznim zajednicama raspršenih migranata (Clifford 1994:304). Pritom treba imati na umu da multilokalna kultura dijaspore nema određenu geografsku granicu nego kulturnu granicu povezanu s kulturom domovine. Iseljenici, jednom odvojeni od domovine geografskom udaljenošću i političkim barijerama, često se nalaze u "graničnim odnosima" s domovinom i suiseljenicama kroz suvremene tehnologije prijevoza, komunikacije i migracije radne snage. Promet, telefonija, internet, TV, radio, video i mobilno tržište rada smanjuju udaljenosti i olakšavaju dvosmjerni promet između dijaspore i domovine pa je danas mnogo lakše živjeti u dva svijeta nego što je bilo prije dva ili više desetljeća. Slijedom toga, Cohen (1996:516) tvrdi da su i suvremeni identiteti dijaspore uglavnom izgrađeni na zamišljenoj osi: "Dijaspore se mogu stvoriti maštom (...) U dobu cyberspacea, dijaspora se može, u određenoj mjeri, održavati ili ponovno stvarati kroz um, kroz kulturne artefakte i kroz zajedničku maštu". I Hrvati u dijaspori vezani su uz domovinu na razne načine, a razvoj modernih komunikacijskih i prometnih mreža potaknuo je njihovu orijentaciju na Hrvatsku putem TV kanala, videa, novina, internetskih sadržaja i letova jeftinih kompanija. Primjerice, u današnje vrijeme moguće je doputovati avionom iz Berlina u Zagreb za samo nekoliko sati i to za nisku cijenu od otprilike $40 €$. Za mnoge u dijaspori, kulturna "prtljaga" donesena od kuće apsolutno je ključni element u konstruiranju identiteta, ali također obuhvaća i obnovljeni skup praksi i diskursa. Reifikacija domaće kulture služi kao društvena strategija pojedinca u dijaspori što je trajni proces promjene gdje prva generacija migranata vlastitu kulturu pretvara u baštinu. Drugim riječima, kao što Baumann (1996:192) pokazuje, dijasporska zajednica kulturne procese pretvara u kulturnu baštinu iz dva razloga - kako bi sebe mogla potvrditi kroz enkulturaciju mlađih generacija te za izgradnju vlastite kulturne utvrde u odnosu na onu većinske kulture. U znanstvenom pismu i govoru korištene termine poput "dijaspore", "dijasporskog identiteta" i "dijasporske svijesti" zamjenjuju učestaliji pojmovi koje koriste ljudi u 
dijaspori u svakodnevnom jeziku ili kako bi opisali svoja iskustva - npr. "naše" i "naši ljudi". Ovo određenje najčešće služi jednoj skupini kako bi mogla kontrastirati sebe i svoj identitet "drugima". Madan iz ovog koncepta izvodi zanimljivu tvrdnju da kao rezultat hibridnosti i fragmentacije, ljudi u dijaspori ne mogu biti "drugi" nijednoj naciji osim samom konceptu "nacije" (2000:33). Artikuliranje dijaspore i kartografiranje ethnoscapesa (Appadurai 1996) u suštini je artikuliranje novih identiteta koji mogu legitimno postojati i koegzistirati izvan surovosti izgradnje nacije. Dakle, dijaspora bi bila konstantan proces pregovaranja nečijeg identiteta kako bismo dobili odgovor na pitanje - tko sam ja? Najčešće, identitet je nešto što se živi i pitanja o njemu su neizravna, a dijaspora nikako nije homogena niti je heterogen skup prepoznatljivih identiteta neovisnih jedan o drugom. Ljudska se bića prisjećaju prošlosti na vrlo selektivan način i grade sadašnjost koja je svojevrstan hibrid više kultura i iskustava. Kao rezultat, ni nostalgija ni raznolikost nisu čiste i jednostavne, a "domovine" koje ljudi imaju tendenciju rekonstruirati često su fiktivne zajednice, dijelom stvarne, a dijelom zamišljene (usp. Rayaprol 2001:164).

Razvidno je da se razmatranje dijaspore kao društvenog oblika ili zajednice u kontekstu procesa disperzije iz središnjeg mjesta ogleda kroz trajno održavanje dva koncepta - domovine (države podrijetla) i prostora doma (osjećaja pripadnosti). To se redovito čini kroz društvene mreže, dijeljenje sjećanja, ekonomske strategije, komunikacije, prometnu povezanost $\mathrm{i}$ institucionalne politike. Na primjer, posjeti domovini često su opisivani kao ključni faktor u olakšavanju ekonomskog i emocionalnog opstanka lokalnih zajednica i dijasporskih mreža (usp. Joseph 2011). Brubaker ističe da diskusije o dijaspori kao fluidnoj, hibridnoj, kreoliziranoj i sinkretičkoj ne uspijevaju objasniti ono što čini zajednice opisane na ovaj način i njima pridružene identitete različitima. Joseph (2012) također smatra da je dijaspora vrlo plodonosan pojam pri razmatranju raznolikih elemenata kulturne baštine gdje je sport svakako jedan od njih. Iako su dijaspore često zamišljene kao bezdomovinske i raseljene, one također "crpe iz načina kulturne proizvodnje kao što je sport kako bi se osjećale kao kod kuće ili smještenima" (Joseph 2012:1). Na gotovo jednak način, Nassy Brown (1998) referira se na kriket kao na "dijasporski resurs" ili aktivnost koja otvara prostor za formiranje kulturnog identiteta, što je situacija koju bismo mogli proglasiti gotovo identičnom onoj s hrvatskom dijasporom i 
nogometom. Dakle, dijaspora se formira kroz kulturne oblike poput glazbe, mode, književnosti, likovne umjetnosti, filma i sporta, kroz elemente koji prelaze granice ili putuju raznim "rutama", a posjeduju sposobnost da ujedine raspršene ljude (usp. Clifford 1997; Gilroy 1994; Hall 1990).

\section{HRVATSKA DIJASPORA I SPORT}

Kod analize dijasporske zajednice i onoga što je povezuje s domovinom, postoji više načina na koje dijaspora stvara svojevrsni "hibrid više kultura $i$ iskustava". Literatura o dijaspori uglavnom daje šest širokih kategorija koje možemo navesti: kulturnu, socijalnu, vjersku, tehnološku, medijsku i kategoriju materijalne potrošnje. Ilustrativan je slučaj kako prva generacija hrvatske dijaspore na različite načine prenosi "hrvatstvo" na svoju djecu, nakon čega slijedi odgovor druge generacije roditeljima i hrvatskoj tradiciji. Drugi je aspekt osobito važan jer treba uzeti u obzir aktivnosti te djece i njihove transkulturalne interakcije, vidjeti što oni čine s tim tradicijama, jesu li ih usvojili i, ako jesu, kako su ih izmijenili da se uklope u novi kontekst te kako će artikulirati svoje identitete u budućnosti. Čest je slučaj da prvi migranti osnuju crkvu ili misiju u cilju dočaravanja "zajednice" koja se temelji na poznatim fenomenima religije i jezika. U nedostatku šire obitelji i rodbine, migranti teže uspostaviti blisku zajednicu na osnovi "monolitnog bratstva sa svojim prepoznatljivim identitetom" (Rayaprol 2001:174).

No, zašto je sport (nogomet) bitan u društveno-humanističkim istraživanjima (hrvatske) dijaspore? Svakako, među iseljenicima i njihovim potomcima u dijaspori, diskurs i konzumiranje nogometa neki su od najvidljivijih elemenata svakodnevnog života i popularne kulture. Iako ne postoji mnogo istraživanja odnosa sporta i identiteta u hrvatskoj dijaspori, australski antropolog Roy Hay objavio je dvije studije koje su se pozabavile stvaranjem nacionalnih klubova na ovom dalekom kontinentu te njihovim utjecajem na ostale aspekte života migranata. Ukratko, Hay zaključuje kako je

"etnički identitet daleko od nekoga iskonskog pečata na pojedincu, plastična i promjenjiva oznaka članstva. Etnički identitet proizvod je brojnih snaga: socijalne isključenosti i stigme te političkog otpora 
prema njima, izrazite kulturne i vjerske baštine kao i novih oblika kulture, lojalnosti obitelji i zajednici, bračnim praksama, koalicijama interesa itd." (Hay 1998:64)

Na osnovi svoje studije hrvatskih imigranata u Geelongu, Hay duhovito primjećuje kako su neposredno poslije useljenja Hrvata u Australiju prvo nastajali nogometni klubovi i crkve, a tek onda folklorna i kulturna društva te političke organizacije. I drugi radovi na temu australskog iseljeništva nude podatke o vrlo visokom broju osnivanja i sudjelovanja Hrvata (i ostalih "Jugoslavena") u sportskim, posebno nogometnim klubovima. Kroz djelatnosti klubova očigledan je i politički moment manifestiran kroz dvije različite hrvatske struje - useljenici pridošli prije Drugoga svjetskog rata koji su većinom lijeve političke orijentacije te oni pristigli 60 -ih i 70-ih godina većinom kao politički emigranti iz Jugoslavije. Između ove dvije struje različitih političkih mišljenja postavlja se problem čiji bi trebao biti primat predstavljanja interesa hrvatske manjine u Australiji. Hrvatski migranti koji su došli u Australiju u neposrednom poslijeratnom razdoblju bili su suočeni s velikim izazovima prilagodbe na novo društvo i okolinu u kojoj su se našli. Većina njih bili su izbjeglice iz Jugoslavije, neki su došli kasnije pod službeno sponzoriranim programom migracije, ali svi su se suočili s problemom uspostave vlastitog identiteta u Australiji. Upravo su hrvatski nogometni klubovi bili među prvima i najrasprostranjenijim institucijama koje su uspostavljali migranti te su odigrali značajnu ulogu u stvaranju i oblikovanju samosvijesti australskih Hrvata te u oblikovanju stavova nehrvatskih Australaca u razdoblju od 1950. do 1995. godine. Kroz takvu situaciju reflektira se i ekonomsko-društvena stvarnost pa Hay navodi primjere hrvatskih mladih imigranata koji se, umjesto uobičajenoga životnog puta priskrbljivanja posla, doma i supruge, u dosta slučajeva unutar nekoliko dana po dolasku odmah okreću pristupanju sportskom kolektivu kako bi se uklopili te pokušali kroz sportski angažman ostvariti navedene ciljeve (Hay 1998:52).

Treba istaknuti i amaterske nogometne aktivnosti, većinom vezane uz iseljeničke klubove Hrvata ili pod pokroviteljskom Hrvatske katoličke misije, kao zanimljiv i vrlo raširen fenomen koji svoju svjetsku ekspanziju doživljava od 1950-ih godina nadalje. Njihova uloga je višestruka, a Sopta (2008:14) naglašava da nisu osnivani samo zbog nogometa 
"već i s ciljem da promiču interese domovine, da razvijaju nacionalnu svijest, da se suprotstave asimilaciji i uz to da postižu zapažene sportske uspjehe”. Korijeni iseljeničkih nogometnih klubova sežu u početak 20. stoljeća, a prvim klubom izvan domovine smatra se Hrvatski orlovi osnovan 1922. u Milwaukeeju, u SAD-u, dok prvi uspjeh postiže NK Sokol osvajanjem prvenstva pokrajine Magallanes u Čileu 1925. godine. Osnivanja iseljeničkih nogometnih klubova diljem svijeta (često imena 'Croatia') tijekom 1960-ih uzima sve više maha te se i institucionalizira u vidu Hrvatskoga nacionalnog nogometnog saveza SAD-a i Kanade osnovanog 1964., Hrvatskoga nogometnog saveza Australije (1974.), Zajednice hrvatskih nogometnih klubova u Njemačkoj (1999.) i relativno recentnoga Europskog vijeća klubova Hrvata pod čijim se okriljem igraju Prvenstvo Europe i Svjetsko prvenstvo. Marin Sopta u svojoj knjizi Sveto ime Croatia donosi kratki pregled svih nogometnih klubova imena Croatia kojih se na svim kontinentima nalazi ukupno 68, a od toga samo u Njemačkoj 27 klubova. Naravno, hrvatski iseljenički nogometni klubovi osim Croatia često nose i imena poput Hajduk, Dinamo, Domagoj, Tomislav, Sokol ili ona koja se pak referiraju na zavičaj (Marsonija, Posavina, Velebit) te je tako njihov sveukupan broj teško ustanoviti. Iako su osnivani većinom s namjerom domoljubnog djelovanja, neki od hrvatskih iseljeničkih nogometnih klubova postigli su i značajne sportske uspjehe, iako im situacija u zemljama prebivanja nije uvijek išla na ruku jer se u većini europskih država etnički klubovi smatraju donekle remetilačkim elementom i kočničarima integracije. No, spomenut ćemo samo nekoliko sportskih uspjeha: NK Metros-Croatia iz Toronta je 1976. postao prvakom NASL-a, tadašnje zajedničke profesionalne nogometne lige SAD-a i Kanade, Croatia Melbourne dvaput je bio prvakom Australije, a u europskim okvirima zanimljiv je uspjeh NK Croatie Malmö koji je u nekoliko godina, od 1982. do 1990., postao redom prvak šeste, pete, četvrte i treće švedske lige tako izborivši igranje u drugoj ligi. U okviru njemačkog sporta, možda i najveći uspjeh jest osvajanje prvenstva Njemačke u futsalu (dvoranskom nogometu) 2010. od strane SD Croatia Berlin. O dinamičnom odnosu hrvatskih iseljeničkih klubova i domovine govori i činjenica da je 10. lipnja 1990. godine NK Hajduk Split na turneji u Australiji, u utakmici s tadašnjim Croatia Melbourneom (danas Melbourne Knights) prvi put od 1945. nastupio u klupskim dresovima bez zvijezde petokrake što je izazvalo 
oduševljenje u publici i odjek među iseljenicima diljem svijeta i domovini te time na određen način nagovijestilo skore političke promjene. Dakako, nisu samo klubovi ti koje možemo smatrati (sportskim) nositeljima identiteta u dijaspori - u posljednje vrijeme u proces su se uključile i reprezentacije hrvatskih manjina iz raznih (europskih) država koje međusobno surađuju na sportskom planu te tako sudjeluju na već redovitom Europskom nogometnom natjecanju reprezentacija hrvatskih nacionalnih manjina koje se održava svakih nekoliko godina od 2006. godine. Posljednje, IV. europsko nogometno natjecanje reprezentacija hrvatskih nacionalnih manjina održalo se od 21. do 23. lipnja 2013. u Vukovaru i Vinkovcima te je uključilo predstavnike Hrvata iz Srbije (Vojvodine), Hrvata iz Mađarske, Hrvata iz Rumunjske, Hrvata iz Slovenije, Hrvata iz Slovačke, Hrvata iz Makedonije, Hrvata iz Austrije (Gradišće), Hrvata iz Crne Gore te Hrvata iz Italije (Molise).

Vezanost iseljenika i domovine na sportskom planu otvara i dosta pitanja - npr. je li sportska reprezentacija državno ili nacionalno predstavništvo? Koji su kriteriji (osim sportskih) za njezino popunjavanje - mogu li u njoj igrati samo oni koji se nacionalno izjašnjavaju kao Hrvati ili je otvorena i za ljude drugih nacionalnosti rođenih u Hrvatskoj? $\mathrm{Na}$ to pitanje teško je dati "ispravan" odgovor, različiti su stavovi o tome, a dosadašnja praksa, ne samo u Hrvatskoj, pokazuje da pravila - nema. Za hrvatsku nogometnu reprezentaciju nastupali su od 1990. Slovenac, Albanac, dva Brazilca, desetak Hrvata rođenih u dijaspori te isto tako desetak Hrvata rođenih u Bosni i Hercegovini. Nisu neuobičajeni i obrnuti slučajevi gdje je, primjerice, Sinjanin Mirko Hrgović nastupao za Bosnu i Hercegovinu, a Zagrepčanin Besart Abdurahimi i Šibenčanin Arijan Ademi odlučili nastupati za reprezentaciju Makedonije iako su bili članovi svih mladih selekcija hrvatske nacionalne vrste, ali nisu nikad dobili priliku u seniorskoj. Zagrepčanin Branko Strupar je od 1999. nastupao za Belgiju, nakon što je te godine postao belgijski državljanin, a isto tako, u povijesti nalazimo i nekoliko primjera nogometnih "prebjega" gdje se ističe Josip Weber, Brođanin, koji je, nakon nekoliko nastupa za Hrvatsku 1992. godine, od 1994. nastupao za belgijsku reprezentaciju, izborivši službenu dozvolu FIFA-e za to jer se nije uspio nametnuti u hrvatskoj reprezentaciji. U svijetu je među poznatijima primjer Jermainea Jonesa (32 god.), sina Nijemice i američkog vojnika rođenog u Frankfurtu, koji je nakon desetak nastupa za (mlađe) njemačke reprezentacije, uvidjevši 
da neće dobiti pravu priliku, odlučio pristupiti američkoj nacionalnoj momčadi. Iako FIFA načelno zabranjuje takva "prebacivanja", Jonesu je odobreno jer nije nastupio ni u jednoj službenoj seniorskoj utakmici nego samo u mlađim kategorijama. Naravno, takav "transfer" pobudio je sukobe mišljenja i u SAD-u gdje su se suprotstavili pobornici teze da Jones kao Nijemac nema što tražiti u reprezentaciji SAD-a i oni koji smatraju da kao sin američkog vojnika, makar rođen i odrastao izvan zemlje, ima svako pravo nastupati za SAD.

\section{NOGOMETNI IDENTITETI I POLITIKA}

Problematika nastupanja za države koje nisu zemlje rođenja pojedinca sve se češće javlja i, ovisno o sportu, zna biti prilično kompleksna. Kao prvo, treba naglasiti da pravila o mogućnostima igrača da predstavlja određenu zemlju nisu jednaka u svim sportovima te se povremeno mijenjaju ili nadopunjuju. Možda i najsloženija jesu ona svjetske nogometne organizacije FIFA-e te ću ih ovdje kratko predstaviti. Pravila za međunarodnu podobnost nogometaša složena su i znatno su se promijenila tijekom vremena i te su promjene imale i popriličan utjecaj na načine kako biti izabran za određenu zemlju. Upravo zato međunarodni sport i jest zanimljiv okvir unutar kojeg se može proučavati nacionalni identitet. Iako se na prvi pogled čini da bi bilo dovoljno svrstati sportaše po putovnici koju imaju, to u svakom slučaju nije pokazatelj njihove nacionalnosti. Ono što dodatno otežava situaciju je i nepostojanju ujednačenih kriterija dobivanja državljanstva što je posebno vidljivo u primjeru Francuske gdje se ti kriteriji baziraju na sprezi teritorijalnosti rođenja (često i prekomorskoj) i državljanstva roditelja, nasuprot njemačkog primjera koji je prilično restriktivan, naglašava krvnu vezu te time otežava građanima rođenim na teritoriju Njemačke dobivanje državljanstva (Holmes i Storey 2004:91). Naravno, državljanstvo se može steći i preko određenog vremena boravka u zemlji ili putem braka, a sve češće dolazi i do toga da mnoge zemlje dopuštaju iznimke pravilima podobnosti, pogotovo u slučajevima vrlo talentiranih sportaša. Također, sve veći broj zemalja dopušta i dvojno državljanstvo te pritom ne zahtijeva odricanje od prvog. Cijeli niz propisa FIFA-e o podobnosti igranja za nacionalnu momčad dostupan je na 
njezinim službenim stranicama, ${ }^{5}$ no ovdje ću samo predstaviti glavne smjernice kako ih je iz izvornika pojednostavio irski list Independent. ${ }^{6}$ Osnovni kriterij da bi netko zaigrao za određenu zemlju jest stalno državljanstvo. Igrač koji ima više od jednog državljanstva, stekne novo ili ima pravo igrati za više zemalja, može, jednom, do svojeg 21. rođendana zahtijevati promjenu zemlje, pod uvjetom da: a) nije igrao u natjecateljskoj utakmici za trenutačnu reprezentaciju, i b) u vrijeme nastupa već je imao državljanstvo zemlje za koju sada želio nastupati. Ako pak igrač želi steći potpuno novo državljanstvo mora zadovoljiti neke od sljedećih uvjeta: a) biti rođen na području Saveza.; b) imati biološku majku, oca, djeda ili baku rođenu na tom području; c) živjeti kontinuirano najmanje pet godina nakon što je navršio 18 godina na području Saveza. Dakle, kao što je vidljivo iz propisa, državljanstvo po načelu srodstva moguće je ostvariti unutar dvije generacije, do linije djeda i bake, što je ovom pravilu donijelo i pomalo podrugljiv naziv "babino pravilo".

Kroz sve navedeno, nogomet je postao jedinstveno djelotvoran medij za usađivanje nacionalnih osjećaja jer se čak i onima koje politika ili javni život ne zanimaju lako identificirati s nacijom kad je simboliziraju mladi ljudi koji se uspješno bave vrhunskim sportom. Nacionalna momčad na taj način dospijeva u središte javnog zanimanja i tada se "zamišljena zajednica koja broji milijune čini stvarnijom u obliku momčadi koju čini jedanaest ljudi s imenom i prezimenom", a svaki pojedinac, pa makar i u ulozi navijača, postaje simbolom svoje nacije (Hobsbawm 1993:156). Ni ostali sportovi nisu pošteđeni rasprava o identitetu - žestoka je rasprava potaknuta u britanskom tisku prema jednom članku u časopisu o cricketu $^{8}$ koji dovodi u pitanje sposobnost igračima rođenima u inozemstvu da igraju za Englesku s dovoljno predanosti. Ovakve rasprave drže pitanja državljanstva i nacionalnog identiteta $u$ fokusu javnosti i osiguravaju svojevrsnu

\footnotetext{
5 http://www.fifa.com/mm/document/affederation/administration/81/10/29/ circularno.1147-eligibilitytoplayforrepresentativeteams_55197.pdf

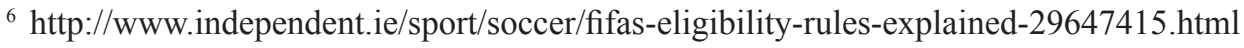

${ }^{7}$ Izvorno u engleskom jeziku: granny rule.

${ }^{8}$ Robert Henderson: “Is It In The Blood?”, Wisden Cricket Monthly, 1995.
} 
zamjenu za rasprave o imigracijskoj politici i odobrenju ili odbijanju statusa izbjeglicama. Konačno, reprezentacija je vrijedna metafora nacije, a u slučaju Irske, primjerice, prihvaćanje nogometa kao dodatnog simbola nacionalnog identiteta odražava ne samo pad važnosti odnosa s Britanijom nego također odražava i potvrdu važnosti irske dijaspore u učvršćivanju identiteta (Holmes 1994). Nogomet učinkovito podržava ovo redefiniranje identiteta i ne samo da osigurava globalnu pozornicu za izražavanje irskog identiteta nego stvaranjem irske nacionalne momčadi odražava jačinu veze između Irske i irske dijaspore (Houlihan 2000:129), što se na gotovo jednak način odvija i u hrvatskom slučaju.

\section{ZAKLJUČAK}

Ovaj je rad za cilj imao propitati identifikacijske procese sportaša, posebice nogometaša, u suvremenom, globaliziranom svijetu, s naglaskom na one rođene u dijaspori. Društveni i kulturni prostor koji stvaraju doseljenici i njihovi potomci možemo nazvati “dijasporskim prostorom” koji simbolički predstavlja most između dijaspore i domovine. U tom prostoru dijaspore, iseljenici dijele "zamišljeni osjećaj pripadnosti" domovini kojoj se priklanjaju kao duhovnoj, kulturnoj i političkoj metafori, no s druge strane, ne treba zanemariti ni razvoj snažnog osjećaja pripadnosti zemlji rođenja. Osim što sam pokušao rasvijetliti pojam dijasporskog identiteta građenog kroz sportsku i nogometnu identifikaciju, pokušao sam istaknuti glavne komponente koje oblikuju dijasporski kulturni identitet. Suvremena dijaspora konstruira i artikulira identitet kroz sredstva globalizacije što joj je omogućeno modernim komunikacijskim i prometnim mrežama, TV kanalima, video-sadržajem, novinama i internetskim sadržajima čime je olakšana i povećana dinamika komunikacije između država. Transnacionalne veze s domovinom i drugim pripadnicima dijaspore na različitim geografskim područjima sve više ublažuju jaz između manjinskih zajednica i većinskih društava. Suvremena sredstva globalizacije ne samo da približavaju domovinu dijaspori nego brišu i udaljenosti između pojedinca i vanjskog svijeta. Suvremena mreža globalizacije pripadnicima dijaspore daje mogućnost uključivanja u različite globalne kulturne struje što stvara svojevrsnu "treću kulturu", utjelovljenu u miješanju 
elemenata iz različitih kulturnih tradicija, izvora i društvenih diskursa. Suvremeni dijasporski identitet ne možemo definirati kao fiksan nego ga treba doživjeti kao stalan proces promjene i transformacije. U ovom smislu, ukorijenjen je i vidljiv kroz pojavu strukture zajednice ogledanu kroz tvrtke, vjerske zajednice, tradicijska društva, sportske klubove i sl. Nadalje, ovaj je rad ustvrdio da se procesi stvaranja kulturnog identiteta među sportašima iz dijaspore uglavnom okreću oko njihova pokušaja formiranja dijasporske svijesti i identiteta utemeljenog na više od jednog mjesta - zemlji rođenja (prebivanja) i “domovini”. U skladu s tim, osjećaj da su članovi "drugačije" zajednice, s povijesnim korijenima i sudbinama izvan vremena i prostora domaćinske nacije, pruža im osjećaj različitosti i ponosa. Brecher i dr. (1993) takve procese nazivaju "globalizacija odozdo", što je karakteristika modernih mreža dijaspore, a posebno je izražena u područjima manje geografske udaljenosti matične zemlje i zemlje rođenja, kao što su primjerice, Hrvatska i Njemačka. Između ostalog, treba reći da sportaši rođeni u dijaspori također stječu i multikulturalnu sposobnost ponašanja na odgovarajući način u nekoliko različitih društvenih prostora. Postoje jezične, društvene i kulturne granice između njihovih životnih svjetova i gotovo su uvijek prisiljeni pregovarati između tih prilično strogo definiranih prostora. U skladu s tim, sportaši iz dijaspore stvaraju svoje kulturne identitete na raskrižju tih zasebnih društvenih prostora, a njihova svijest često izvire iz migracijskog iskustva njihovih roditelja koje je često podijeljeno između napuštene domovine i zemlje migracije.

\section{LITERATURA}

ANDERSON, Benedict. 1983. Imagined communities: reflections on the origin and spread of nationalism. London: Verso.

APPADURAI, Arjun. 1996. Modernity at large: cultural dimensions of globalization. Minneapolis: University of Minnesota Press.

BAUMANN, Gerd. 1996. Contesting culture: discourses of identity in multi-ethnic London. Cambridge: Cambridge University Press.

BLANCHARD, Kendall. 1995. The anthropology of sport: an introduction. Westport, Conn.: Bergin \& Garvey.

BONIFACE, Pascal. 2002. La Terre est ronde comme un ballon: géopolitique du football. Paris: Éditions du Seuil. 
BRECHER, Jeremy, John BROWN CHILDS i Jill CUTLER. 1993. Global visions: beyond the new world order. Boston: South End Press.

BRENTIN, Dario. 2013. "A lofty battle for the nation: the social roles of sport in Tudjman's Croatia”. Sport in Society: Cultures, Commerce, Media, Politics, vol. 16/8:993-1008. DOI: 10.1080/17430437.2013.801217

BROMBERGER, Christian, Alain HAYOT i Jean-Marc MARIOTTINI. 1995. Le match de football: ethnologie d'une passion partisane à Marseille, Naples et Turin. Paris: Maison des sciences de l'homme.

BRUBAKER, Rogers. 2005. “The 'Diaspora' Diaspora”. Ethnic and Racial Studies, vol. 28/1:1-19. DOI: 10.1080/0141987042000289997

CLIFFORD, James. 1994.“Diasporas”. Cultural Anthropology, vol. 9/3:302-338. DOI: 10.1525/can.1994.9.3.02a00040

CLIFFORD, James. 1997. Routes: travel and translation in the late twentieth century. Cambridge: Harvard University Press.

COHEN, Robin. 1996. "Diasporas and the nation-state: from victims to challengers". International Affairs, vol. 72/3:507-520. DOI: 10.2307/2625554

ELIAS, Norbert i Eric DUNNING. 1966. "Dynamics of sport groups with special reference to football". British Journal of Sociology, vol. 17/3:388-402. DOI: $10.2307 / 589186$

ELIAS, Norbert i Eric DUNNING. 1986. Quest for excitement: sport and leisure in the civilizing process. Oxford: Basil Blackwell.

FRANK, Sybille i Silke STEETS. 2010. Stadium Worlds Football, Space and the Built Environment. Hoboken: Taylor \& Francis.

GILROY, Paul.1994. “Diaspora”. Paragraph, vol. 17/3:207-212. DOI: 10.3366/ para.1994.17.3.207

GIULIANOTTI, Richard. 1999. Football - A Sociology of the Global Game. Malden: Blackwell Publishers Ltd.

HALL, Stuart. 1990. “Cultural Identity and Diaspora”. U Identity, Community, Culture, ur. J. Rutherford. London: Lawrence and Wishart, 22-37.

HARGREAVES, John. 2000. Freedom for Catalonia: Catalan nationalism, Spanish identity and the Barcelona Olympic Games. Cambridge: Cambridge University Press.

HAY, Roy. 1998. "Croatia: community, conflict and culture: the role of soccer clubs in migrant identity". Immigrants \& Minorities, vol. 17:49-66. DOI: 10.1080/02619288.1998.9974928

HOBSBAWM, Eric J. 1993. Nacije i nacionalizam: program, mit, stvarnost. Zagreb: Novi Liber. 
HOLMES, Michael. 1994. "Symbols of national identity and sport: The case of the Irish football team". Irish Political Studies, vol. 9/1:81-98. DOI: $10.1080 / 07907189408406525$

HOLMES, Michael i David STOREY. 2004. "Who are the boys in green? Irish identity and soccer in the Republic of Ireland". U Sport and national identity in the postwar world, ur. Adrian Smith i Dilwyn Porter. London: Routledge, 88-104.

HOULIHAN, Barrie. 2000. "Politics and Sports". U Handbook of Sports Studies, ur. J. Coakley i E. Dunning. London: Sage Publications, 213-227.

JOSEPH, Janelle. 2011. “A Diaspora Approach to Sport Tourism”. Journal of Sport \& Social Issues, vol. 35/2:146-167. DOI: 10.1177/0193723511406130

JOSEPH, Janelle. 2012. "Culture, community, consciousness: The Caribbean sporting diaspora”. International Review for the Sociology of Sport, vol.49/6:1-19. DOI: $10.1177 / 1012690212465735$

KOKOVIĆ, Dragan. 1986. Sport bez igre. Titograd: Univerzitetska riječ.

KOTNIK, Vlado. 2009. "Sport and nation in anthropological perspective: Slovenia as land of skiing nationhood". Antropologija, vol. 7:53-66.

KUMAR, Krishan. 2003. The making of English national identity. Cambridge: Cambridge University Press.

MADAN, Manu. 2000. “'It's Not Just Cricket!' World Series Cricket: Race, Nation, and Diasporic Indian Identity”. Journal of Sport \& Social Issues, vol. 24/1:24-35. DOI: $10.1177 / 0193723500241003$

MANGAN, J. A. 1996. Tribal identities: nationalism, Europe, sport. London: Frank Cass.

MÜLLER, Denis. 2006. "Le football: entre la violence et le sacré un sport-spectacle révélateur de l'état du monde". Évangile et liberté, vol. 199 (http://www.evangileet-liberte.net/elements/numeros/199/article9.html, posjećeno 20.4.2015.)

MÜLLER, Denis. 2008. Le football, ses dieux et ses démons: menaces et ajouts d'un jeu déréglé. Genève: Labor et Fides.

NASSY BROWN, Jacqueline. 1998. "Black Liverpool, Black America, and the gendering of diasporic space". Cultural Anthropology, vol. 13:291-325. DOI: 10.1525/ can.1998.13.3.291

NAURIGHT, John. 1995. Sport, power and society in New Zealand: historical and contemporary perspectives. Sydney: Australian Society for Sports History.

PALMER, Catherine. 2002. Anthropology and sport. Sydney: Australian Anthropological Society.

PERASOVIĆ, Benjamin i Sunčica BARTOLUCI. 2007. "Sociologija sporta u hrvatskom kontekstu”. Sociologija i prostor, vol. 45/175 (1):105-119.

RAYAPROL, Aparna. 2001. “'Can you talk Indian?' Shifting notions of community and identity in the Indian diaspora". U Community and Identities: Contemporary 
Discourses on Culture and Politics in India, ur. Surinder S. Jodhka. New Delhi: Sage Publications, 163-190.

SANDS, Robert. 1999. Anthropology, sport, and culture. Westport, Conn.: Bergin \& Garvey.

SANDS, Robert. 1999. GutCheck!: an anthropologist's wild ride into the heart of college football. Carpinteria, Calif.: Rincon Hill Books.

SOPTA, Marin. 2008. Sveto ime Croatia: hrvatski nogometni klubovi "Croatia” u iseljeništvu. Zagreb: Udruga "Hrvatska Dijaspora".

VERTOVEC, Steven i Robin COHEN, ur. 1999. Migration, Diasporas, and Transnationalism. Cheltenham: Edward Elgar.

Tibor Komar

\section{IDENTITY AND/THROUGH SPORTS: ANTHROPOLOGICAL APPROACH} TO THE RESEARCH OF DIASPORA

Through the prism of sports, more specifically football, the author discusses several segments of the connection of sports and identity in diaspora communities. After the introduction, where he presents the short history of research and scientific interest for sports in anthropology and related sciences, the author analyses the elements of the process of the construction of the national identity in Croatian diaspora related to amateur and professional football.

Keywords: identity, sports, football, diaspora 